\title{
Apprentice Researchers at QUEST
}

In an effort to encourage young adults to choose a career in science, a high school student program has been developed at the National Science Foundation (NSF) Science and Technology Center for Quantized Electronic Structures (QUEST) at the University of California at Santa Barbara. The six-week summer program, which incorporates each student into a graduate-level lab project, enables high school juniors to appreciate the excitement of new discoveries along with the effort and interactions required for fruitful research. When the program was initiated, the graduate students and professors were skeptical that high school students would be able to understand or contribute to the ongoing lab research. Most students had taken only one chemistry or physics course. From our experiences during the first two summers, however, we find that the students surpass all expectation. In fact, some become so valuable to their labs that they are hired as assistants in their senior year of high school.

The primary goals of the apprentice researcher program are to:

- have students gain confidence in their ability to contribute to a research project,

- teach them as much science as they are able to learn,

- excite students about research, and

- teach them to talk about their scientific work, both casually and formally.

Though we select students who have already expressed some interest in science, their confidence level for tackling lab research ranges from tentative to extremely ambitious. We take this variation into account when we match each student with a graduate student mentor and a project. Each project includes some early experimental tasks that are easy to learn and require little knowledge of the science involved. This allows the students to feel a sense of accomplishment early in the program. In addition, they take a crash course in electronics, computer programming, and semiconductors (the majority of the projects involve gallium arsenide) during the first three weeks of the program. Such courses provide the foundation and vocabulary to enable the students to work safely in the lab and understand more about their graduate mentor's experiments.

Since we want to take students as far as they can go intellectually without overwhelming them, we encourage them to ask their mentors as many questions about the related science as they can. It can be difficult to estimate students' comprehension of the material when the primary means of teaching is verbal. The mentors, therefore, use many approaches to probe understanding, including quizzing the students informally on the previous day's events, encouraging the students to write a brief description of their project, or asking them to report on how to operate one of the lab instruments. Students also keep a current lab notebook. This constant exchange helps them understand the science and experimental procedures in more detail since the gaps in their knowledge are readily apparent from their answers. In addition, the mentors provide reference materials to keep at home such as "Discovery" articles and freshman-level chemistry, physics, and materials text books.

Sharing the excitement of discovery with the students proves to be more difficult. The most exciting moments in scientific research rarely happen between the hours of nine and five and thus, when interesting results are anticipated, many graduate mentors ask their students to stay late, or come back to the lab to share in the experience. We find that the high school student's enthusiasm is closely correlated to the excitement the graduate mentor has for her or his work, regardless of whether or not the team is involved in an important discovery.

Some students make significant contributions to QUEST lab research. One of the most successful students in our program learned how to do scanning tunneling microscopy on semiconductors in ultrahigh vacuum. She took responsibility for certain tasks such as tip preparation, sample preparation, and computer analysis of images obtained. This student reported that her lab experience con-

The Education Exchange highlights the experiences of scientists and engineers with local schools, along with helpful hints and resources. If you would like to share your own involvement in science education, contact Finley Shapiro, Department of Electrical and Computer Engineering, Drexel University, Philadelphia, PA 19104, U.S.A.

Telephone (215) 895-6749

Fax (215) 895-1695

Email: shapiro@ece.drexel.edu vinced her that she wants to be a chemistry major. As a high school senior she is taking her first physics course in preparation for college entrance.

Another student carried out his own experiments in photochemical etching-a valuable fabrication tool for III- $V$ semiconductor structures used in devices such as lasers and transistors. His experiments resulted in a detailed calibration of some of the chemical solutions used in the etch process. These results have proven valuable both in understanding the role of the solution in the overall etch process and in deciding the best etchant to use for particular applications of the technique. This student is still a lab assistant at QUEST and has completed data analysis for a paper on which he is a joint author. He was recently admitted to the College of Engineering for September 1993.

While the students spend most of their time doing lab work, we also consider it important to teach them to talk about science-casually with their parents and friends, and formally in front of their peers, mentors, and relevant professors. Casual conversation is encouraged by having informal meetings every morning at which the students discuss their projects with each other. They are asked regularly to explain two new vocabulary words to the group. This meeting is monitored by a person familiar with all of the projects so that if a student is expressing confusion, the mentor can be alerted and can try to troubleshoot the problem. The students also give two formal presentations on their research project: a fifteenminute talk halfway through the program, and a thirty-minute talk at the end. The quality of these talks, which include viewgraphs and slides prepared with the mentor's help, indicate to us that the students achieve more than anyone would have anticipated. They present an impressive amount of information in a clear and organized fashion. Furthermore, they leave the summer program with a clear idea of the experimental process, the collaborative nature of research, and the kind of work required to gain information about a given system.

In summary, we believe that high school students can contribute to graduate-level projects if the students are properly motivated, if the project includes initial tasks they can readily complete, and if the graduate mentor conveys the necessary information, feedback, and excite- 
ment. In addition, teaching students to talk about science casually and formally encourages them to be ambassadors for scientific research at their schools and in their communities.

\section{Acknowledgments}

We wish to thank Jim Merz, director of QUEST, and N. Dagli, E. Hu, R. Martin, G. Stucky, and H. Weinberg for their part in designing research opportunities. This program is supported by the Education and Human Resources Directorate of the National Science Foundation through a supplemental grant to the NSF Science and Technology Center for Quantized Electronic Structures, Grant \#DMR 9120007.

VALERIE BRESSLER-HILL FIONA GOODCHILD

Valerie Bressler-Hill is a PhD candidate in chemistry at the University of California at Santa Barbara.

Fiona Goodchild is Education Outreach Director of QUEST.

To receive additional information on how you can get involved in enhancing $\mathrm{K}-12$ science education, circle number 120 on the Reader Service Card

To: MRS Members

Re: Meeting Information You May Not Have Received

It has come to our attention that some members may not have received current information mailed from MRS, in particular, the most recent call for papers. If these important documents are not reaching you, please notify us by mail or fax:

\section{Materials Research Society 9800 McKnight Road Pittsburgh, PA 15237}

FAX (412) 367-4373

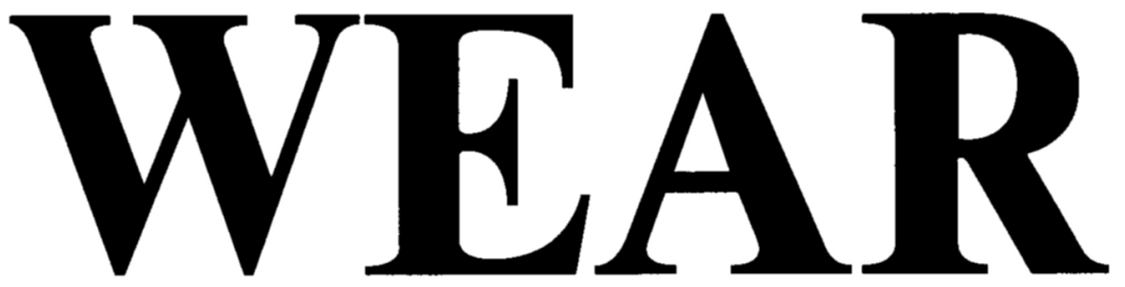

\section{An International Journal on the Science and Technology of Friction, Lubrication and Wear}

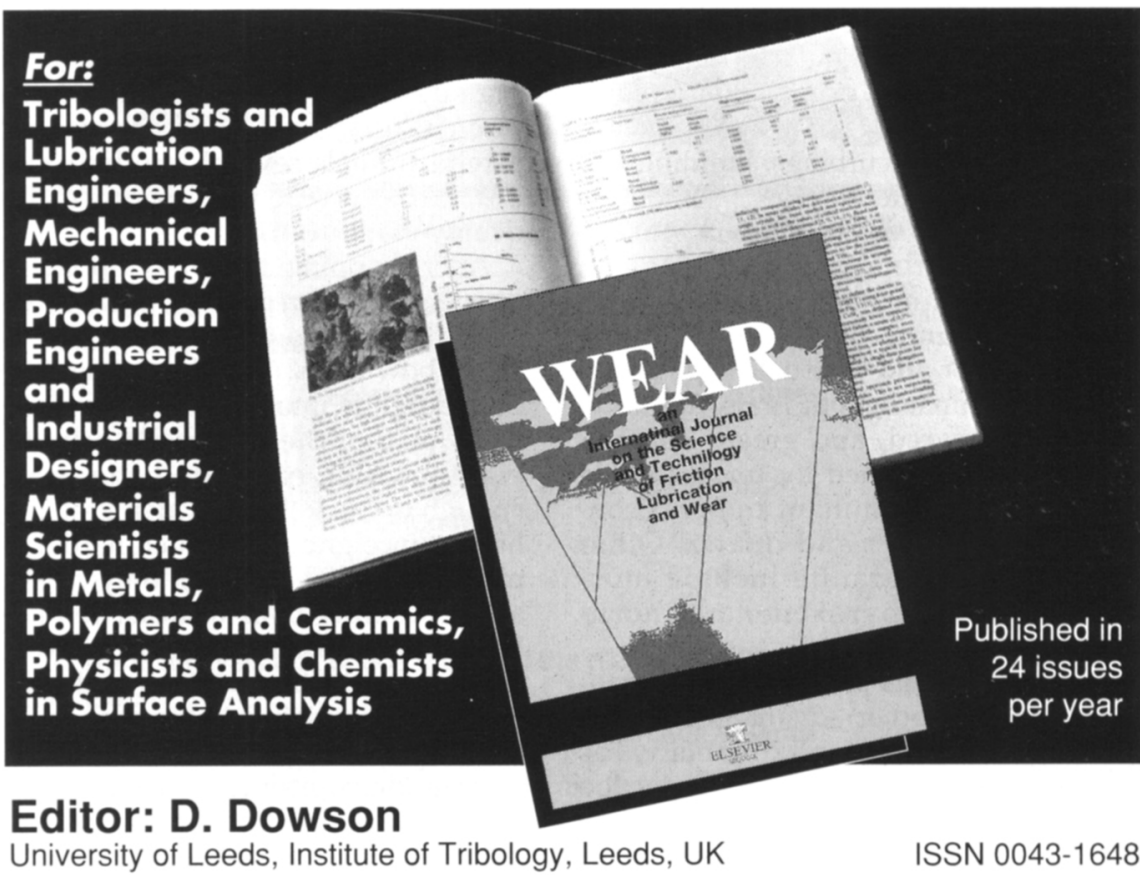

This international journal is dedicated to the rapid publication of high quality papers on the important subjects of wear and friction together with papers on related aspects of lubrication. Thorough refereeing of all papers in accordance with procedures for international journals in science and engineering, ensures that Wear is an international forum for multidisciplinary communications on topics such as:

- The fundamental knowledge of wear phenomena as applied to engineering and science, including nanometer and atomic scale aspects of tribology, design and materials oWear of natural biological and implanted materials - Contact phenomena, control and prevention of wear processes $-\mathrm{New}$ materials and their characteristics in terms of surface structure, wear, corrosion, oxidation resistance, friction and high temperature strength oNew engineering concepts and innovation in materials (plastics, composites, ceramics) - Controlled wear by abrasion oWear of cutting and forming tools OLubricants and mechanisms of lubrication controlling wear and friction esurface phenomena, their physics, chemistry and practical consequences.

ELSEVIER

S E Q U O I A

PO Box 564

$\mathrm{CH}-1001$ Lausanne 1

Switzerland

Tel.: +41 (21) 207381

Fax: +41 (21) 232545

ए

Please send detailed information on WEAR

Name:

Company/Institute:

Street:

Country:

Date:
For customers in the USA and Canada Elsevier Science Publishing Co., Inc. Journal Information Center 655 Avenue of the Americas New York, NY 10010, USA Tel.: +1 (212) 633-3750 Fax: +1 (212) 633-3764 